\section{P38 THE IMPACT OF ETHNICITY ON SPECIFIC AIRWAYS RESISTANCE (SRAW) IN CHILDREN}

doi:10.1136/thoraxjnl-2012-202678.179

J Kirkby, R Bonner, S Lum, S Sonnappa, J Stocks. UCL, Institute of Child Health, London, UK

Introduction Plethysmographic Specific Airways Resistance (sRaw), which can be measured during tidal breathing without need for airway occlusion. ${ }^{[1]}$ has been shown to discriminate between young healthy children and those with lung disease. Recent recommendations and reference data were, however, based on data from White children. ${ }^{[2]}$ This could potentially bias interpretation if applied to children of other ethnicities. Nevertheless, since ethnic differences in lung and airway function have been shown to be proportional, ${ }^{[3]}$ and since sRaw is internally adjusted for differences in resting lung volume, we hypothesised that there would be no ethnic differences in sRaw.

Aim To compare sRaw between healthy Black and healthy White children of similar age.

Methods Fifty-six healthy Black children (64\% male, mean (SD) age: 8.3(1.1) years) and 148 healthy White children (50\% male, mean (SD) age: 7.3(1.4) years) underwent sRaw measurements in accordance with recent recommendations. ${ }^{[2]}$ Results were expressed as Z-Scores to adjust for height, sex and age. ${ }^{[2]}$ Paired t-tests were used to determine the impact of ethnicity on sRaw.

Results There were no significant differences in sRaw between healthy Black children and healthy White children $(p=0.22)$. The mean $(95 \% \mathrm{CI})$ difference (Black-White) for specific effective airways resistance (sReff) ${ }^{[2]}$ was -0.2 Z-Scores $(0.5 ; 0.1)$ (figure 1).

Conclusion Since ethnic differences in sRaw do not occur, published sRaw reference equations derived from White children should be equally applicable when assessing Black children with lung disease.

\section{References}

1. Dab \& Alexander, Pediatr Res, 1976.

2. Kirkby, ERJ, 2010

3. Quanjer ERJ 2012

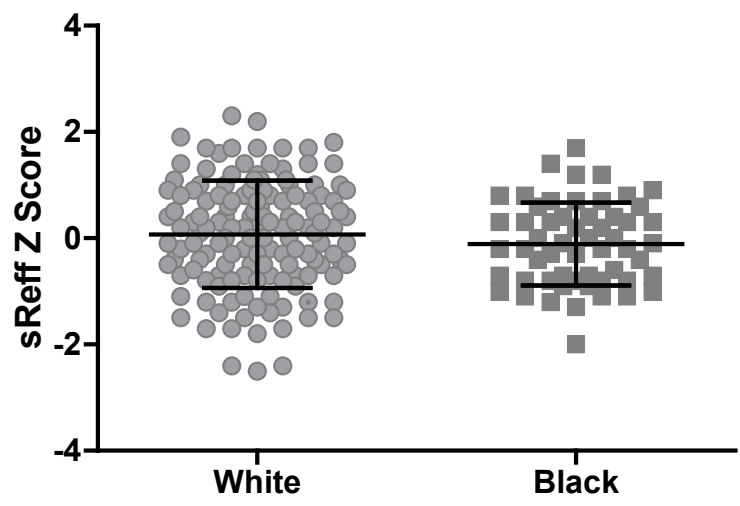

Abstract P38 Figure 1 Comparison of sReff Z-Scores in healthy White and Black children (Black lines denotes mean \pm SD)

\section{P39 VENTILATORY RESPONSE AMONGST SCUBA DIVERS AND NON-DIVERS}

doi:10.1136/thoraxjnl-2012-202678.180

${ }^{1} \mathrm{CMN}$ Earing, ${ }^{2} \mathrm{DJ}$ McKeon, ${ }^{1} \mathrm{H}-\mathrm{P}$ Kubis. ' $S$ School of Sport, Health and Exercise Science, Bangor; ' University, Bangor, Wales, Respiratory Department, Ysbyty Gwynedd, BCUHB, Bangor, Wales
Purpose To investigate the ventilatory response to $\mathrm{CO}_{2}$ in hyperoxia, hypoxia, and during exercise amongst experienced scuba divers and matched controls.

Methods Three studies were performed comparing the ventilatory response to $\mathrm{CO}_{2}$ of experienced scuba divers with non-diving matched controls. The first study measured the ventilatory recruitment threshold (VRT) during $\mathrm{CO}_{2}$ rebreathing in hyperoxia of experienced divers $(n=10)$ and controls $(n=10)$; the second study investigated the $\mathrm{CO}_{2}$ sensitivity in rest and exercise using $\mathrm{CO}_{2}$ rebreathing in hyperoxia at a workload designed to mimic the load of diving with scuba divers $(n=11)$ and controls $(n=11)$. The third study examined the respiratory drive of scuba divers $(n=10)$ and controls $(n=10)$ whilst breathing four different gas mixtures balanced with $\mathrm{N}_{2}$ (ambient air; $25 \% \mathrm{O}_{2} / 6 \% \mathrm{CO}_{2} ; 13 \% \mathrm{O}_{2} ; 13 \% \mathrm{O}_{2} / 6 \%$ $\mathrm{CO}_{2}$ aimed to assess the combined response to hypercapnia and moderate hypoxia.

Results Experienced divers possessed a higher VRT $(P<0.05)$ coinciding with the accumulation of $7 \%{ }^{\text {ins }} \mathrm{CO}_{2}\left(\mathrm{pCO}_{2 \text { cap }}=53.20 \pm 2.20\right.$ $\mathrm{mm} \mathrm{Hg}$ ) during $\mathrm{CO}_{2}$ rebreathing compared to controls with VRT occurring at $6 \%{ }^{\text {ins }} \mathrm{CO}_{2}\left(\mathrm{pCO}_{2 \text { cap }}=44.72 \pm 1.74 \mathrm{~mm} \mathrm{Hg}\right)$. Exercise at a load typical for diving was found to have no effect on the ventilatory sensitivity to $\mathrm{CO}_{2}$ in divers (rest: $1.49 \pm 0.33$; exercise: $1.22 \pm 0.55$ [1/ $\left.\mathrm{min} \mathrm{x} \mathrm{mmHg}^{-1}\right]$ ) and controls (rest: $2.08 \pm 0.71$; exercise: $2.05 \pm 0.98$ $\left.\left[1 / \mathrm{min} \mathrm{x} \mathrm{mmHg}^{-1}\right]\right)$ while differences in sensitivity remained between the groups $(P<0.05)$. Inspiration of the four test gas mixtures revealed there was no contribution of the tested oxygen pressures to the difference in ventilatory sensitivity to $\mathrm{CO}_{2}$ between divers and controls.

Conclusion Divers possess a lower ventilatory response to $\mathrm{CO}_{2}$ which was not affected by exercise or the tested oxygen pressures suggesting an adaptation of central $\mathrm{CO}_{2}$ sensitivity.

Key Words: Diving, hypercapnia, hypoxia, chemo sensitivity, exercise

\section{P40 CHANGE IN RECTUS FEMORIS CROSS SECTIONAL AREA (RFCSA) FOLLOWING AN ACUTE EXACERBATION OF CHRONIC OBSTRUCTIVE PULMONARY DISEASE (AECOPD)}

doi:10.1136/thoraxjnl-2012-202678.181

'S Mandal, 'E Suh, 'B Connolly, 'M Ramsay, ${ }^{2} Z$ Puthucheary, ${ }^{2} \mathrm{~J}$ Moxham, 'N Hart. 'Lane-Fox Respiratory Unit, London, UK; ${ }^{2}$ King's College London, London, UK

Introduction Ultrasound (US) is a useful tool in measuring RFcsa. We have previously shown that a curvilinear ultrasound probe (CUP) is equally effective as a linear ultrasound probe in measuring RFcsa (Mandal et al 2011). We therefore used a CUP-US to characterise the trajectory of muscle loss in a cohort of patients with AECOPD

Methods Subjects had RFcsa measured at 3/5 of the distance from the anterior superior iliac spine to the superior border of the patella during a hospital admission with AECOPD and at 4 weeks post hospital discharge. Image acquisition was made using real time B-mode ultrasonography using a $2-5 \mathrm{MHz}$ curvilinear probe (SonoSite Inc, Japan). RFcsa measurements were calculated offline using the Image J® programme. Subjects also wore an Actiwatch Spectrum device (Phillips Respironics, Murrysville, Pennsylvania) to monitor physical activity levels during exacerbation and recovery.

Results 10 patients were recruited. $40 \%$ were male with an age of $71 \pm 11$ years and $\mathrm{FEV}_{1} 0.6 \pm 0.12 \mathrm{~L}$ (on admission). RFcsa at admission was $519 \pm 359 \mathrm{~mm}^{2}$. Mean change in RFcsa between admission and follow up was $-90 \pm 295 \mathrm{~mm}^{2}(19.5 \%)$. Subjects were divided in to 2 groups based on a 10\% reduction in RFcsa (see table 1). Small numbers of patients prevented statistical analysis of the data. However, patients with $\geq 10 \%$ RFcsa loss tended to be older, had a lower BMI and longer length of hospital stay. At discharge this group of patients had lower daily physical activity count and 